\title{
O atraso tecnológico da América Latina como decorrência de aspectos geográficos e de fatores microeconômicos interligados ${ }^{1}$
}

\author{
Paulo Roberto Feldmann ${ }^{2}$
}

\begin{abstract}
Resumo
O presente artigo trata da relação entre as condições geográficas de uma determinada região e o surgimento de inovações, com o objetivo de analisar as causas para o atraso da América Latina nas questões referentes ao desenvolvimento tecnológico. O texto aborda o problema olhando para as maiores empresas da região, discutindo qual a explicação para o fato de estas raramente estarem nos setores classificados como de alta tecnologia. Para buscar essa explicação, o artigo percorre vários autores que se debruçaram sobre o tema detendo-se, principalmente, naqueles que fizeram comparações com outras regiões do globo, mormente os países asiáticos, tendo em vista caracterizar os aspectos geográficos decisivos para a ocorrência de inovações. O resultado é altamente preocupante, pois são raras as empresas da América Latina que conseguem projeção mundial e as mesmas, quase sempre, fazem parte de setores da economia de conteúdo tecnológico muito baixo.
\end{abstract}

Palavras-chave: Geografia; Inovação; América Latina; Ambiente empresarial; Atraso tecnológico.

\section{Abstract \\ The technological backwardness of Latin America as a consequence of geographical and microeconomics related factors}

The present paper deals with the relation between geographical conditions in a specific region and the occurrence of innovations. The objective is to analyze the reasons for the backwardness of Latin America in matters related to technology development. The article's approach is to observe the largest companies of the region, trying to understand why they almost never are part of the high technology industries. In order to get these explanations, the article mentions many authors that have dedicated themselves to this subject, paying more attention to those who had made comparisons with other regions in the world, specially Asia. The aim here was to characterize the geographic circumstances that were decisive to the occurrence of innovations. The results are deeply alarming not only because of the low number of Latin American companies that have reached worldwide recognition, but also because, almost always, these few companies came from where the technology content is very low.

Key words: Geography; Innovation; Latin America; Business environment; Technological delay. JEL O120, O310.

(1) Trabalho recebido em junho de 2007 e aprovado em dezembro de 2007.

(2) Professor da Faculdade de Economia e Administração da Universidade de São Paulo (FEA. USP), São Paulo, SP, Brasil/ex-Diretor de Assuntos Corporativos da Microsoft do Brasil (2003-2008). E-mail: <feldmann@usp.br>. 


\section{Introdução}

A importância do efeito da tecnologia no desempenho e na competitividade das empresas é indiscutível: hoje novos produtos e processos dão às empresas a possibilidade de compensar seus fatores escassos ou fraquezas. E esses novos produtos e processos são obtidos por intermédio da tecnologia. Se repararmos na competição existente na maioria dos setores da economia, veremos que as empresas que são bem-sucedidas são as que conseguem usar bem as novas tecnologias, e, de preferência, antes que seus concorrentes o façam.

A tecnologia diminuiu muito a importância dos antigos fatores de produção considerados fundamentais. As vantagens clássicas, como salários baixos, matérias-primas abundantes, capital barato ou os grandes mercados internos foram completamente anulados pela competição global que hoje prevalece entre as nações. O novo paradigma da competição é baseado na capacidade dos países e de suas respectivas empresas de inovarem. No entanto, como pretendemos mostrar, as empresas latino-americanas investem muito pouco em Pesquisa \& Desenvolvimento e raramente atuam nos setores denominados de alta tecnologia. Governos têm responsabilidade nesse fato, por não contribuírem para criar um ambiente empresarial apropriado para o surgimento de inovações. Mas talvez a principal causa para essa inapetência tecnológica esteja na própria geografia da região. O presente artigo pretende examinar justamente essa relação entre o espaço latino-americano e a ocorrência de inovações tecnológicas.

\section{A importância das condições geográficas no surgimento de inovações tecnológicas}

O que torna alguns lugares do mundo mais propensos à inovação do que outros? David Landes (1998) pergunta por que a Revolução Industrial aconteceu na Europa e mais especificamente na Grã-Bretanha, e não em outros países. O próprio Landes responde com razões de ordem cultural, histórica e geográfica, mas enfatiza que na Grã-Bretanha de meados do século XIX havia uma crescente autonomia da investigação intelectual combinada com um enorme interesse acerca do que na época se chamava "a invenção da invenção", e que Landes denomina de rotinização da invenção. Esse aspecto acabou sendo o motor que desencadeou o surgimento de inúmeras descobertas científicas e inovações tecnológicas por parte da Grã-Bretanha e que resultou no domínio britânico sobre a economia mundial no final do século XIX.

Apesar de, ao longo do século XX, vários economistas se dedicarem a explicar o crescimento econômico como algo muito ligado à localização das cidades e países, destacando-se Marshall (1920) como um dos pioneiros nesse tema, foi somente nos últimos 15 anos que cresceu a consciência por parte de 
alguns autores importantes como Paul Krugman (1995), Peter Dicken (1998) ou Michael Porter (1993) a respeito da importância das condições geográficas no desenvolvimento econômico. A razão para essa conscientização tem várias explicações, mas uma delas refere-se ao fato de que o progresso e as melhorias das condições de vida têm se concentrado de forma acentuada em algumas regiões do globo, por sinal, a grande maioria situada no hemisfério norte.

A análise da relação entre a mudança tecnológica e o desenvolvimento econômico também não é um assunto novo, tendo sido um dos temas principais de J. Schumpeter, um dos maiores economistas do inicio do século XX. Para Schumpeter (1943), a economia está normalmente em estado de equilíbrio em seus fluxos de capital, mas a atividade empreendedora e a inovação alteram essa tendência criando monopólios temporários e gerando riquezas. Após algum tempo, como decorrência de a inovação tornar-se madura e de outros competidores adentrarem o mercado, o equilíbrio torna a voltar, para, então, conseqüientemente, surgir outra inovação acompanhada de um empreendedor, a qual causará uma destruição criativa, mudando novamente a ordem econômica vigente. Ou seja, segundo Schumpeter, as inovações têm o poder de alterar equilíbrios existentes em setores e até destruí-los totalmente para colocar algo novo em seu lugar. Não resta dúvida de que Schumpeter continua atual. Também datam do início do século XX as análises do economista russo Kondratiev. Como se sabe, Kondratiev (1925) foi o responsável pelo conceito de que o crescimento econômico ocorre em ondas, e cada uma delas tem uma duração aproximada entre 50 e 60 anos. Cada uma dessas ondas está associada a alguma importante mudança tecnológica. Já aconteceram quatro ondas e estamos agora na metade da quinta, conforme mostrado no Quadro 1. Kondratiev dizia que a mudança tecnológica que caracteriza cada onda tem um impacto enorme sobre toda a economia e a sociedade no período da sua vigência. Cada onda, segundo ele, teria quatro subfases: 1. prosperidade com crescimento; 2. recessão; 3. depressão; e 4. decadência com substituição por uma nova onda. Assim sendo, inicialmente a nova onda provoca um grande crescimento econômico e enormes mudanças na sociedade, incluindo quebra de paradigmas e mudanças culturais. No entanto, ao final do período, a demanda começa cair, além de haver uma saturação devido ao grande número de empresas competindo entre si. Nesse momento, os investimentos também diminuem, as empresas se concentram em racionalização e o desemprego aumenta. É quando começa a surgir a próxima onda com base no surgimento de alguma nova tecnologia revolucionária. O Quadro 1 mostra as características principais das quatro ondas anteriores e da que estamos vivenciando agora, a quinta, que é a onda da Tecnologia da Informação.

A última linha do Quadro 1 mostra justamente quais países se deram melhor em cada uma das cinco ondas. Dicken (1998), ao analisar os ciclos de 
Kondratiev, ressalta que em cada uma das fases uma dada mudança tecnológica predominou e permitiu que algumas nações crescessem bem mais que outras. Concluindo assim que só esse fator já seria suficiente para que a questão geográfica fosse mais bem compreendida no sentido de se tentar entender como surgem as inovações tecnológicas. Ou seja, a questão crucial é por que as inovações tecnológicas são muito freqüentes em algumas regiões e escasseiam ou não existem em outros espaços geográficos.

Quadro 1

As 5 ondas de Kondratiev

\begin{tabular}{|c|c|c|c|c|c|}
\hline Onda & Primeira & Segunda & Terceira & Quarta & Quinta \\
\hline $\begin{array}{l}\text { Início e } \\
\text { Término }\end{array}$ & $\begin{array}{c}1770 / 80 \mathrm{a} \\
1830 / 40\end{array}$ & $\begin{array}{c}1830 / 40 \mathrm{a} \\
1880 / 90\end{array}$ & $\begin{array}{c}1880 / 90 \mathrm{a} \\
1920 / 30\end{array}$ & $\begin{array}{c}1920 / 30 \mathrm{a} \\
1970 / 80\end{array}$ & $1970 / 80$ a ? \\
\hline Descrição & Mecanização & $\begin{array}{c}\text { Força a vapor } \\
\text { e ferrovia }\end{array}$ & $\begin{array}{l}\text { Energia elétrica, } \\
\text { engenharia pesada }\end{array}$ & $\begin{array}{c}\text { Produção em } \\
\text { massa, } \\
\text { "fordismo" }\end{array}$ & $\begin{array}{l}\text { Tecnologias da } \\
\text { informação }\end{array}$ \\
\hline Fator-chave & $\begin{array}{c}\text { Algodão e } \\
\text { ferro fundido }\end{array}$ & $\begin{array}{l}\text { Carvão e } \\
\text { transporte }\end{array}$ & Aço & $\begin{array}{l}\text { Petróleo e } \\
\text { derivados }\end{array}$ & $\begin{array}{c}\text { Microeletrônica, } \\
\text { tecnologia } \\
\text { digital }\end{array}$ \\
\hline $\begin{array}{l}\text { Setores } \\
\text { alavanca- } \\
\text { dores de } \\
\text { crescimento }\end{array}$ & $\begin{array}{c}\text { Têxteis e seus } \\
\text { equipamentos, } \\
\text { fundição e } \\
\text { moldagem de } \\
\text { ferro, energia } \\
\text { hidráulica }\end{array}$ & $\begin{array}{c}\text { Máquinas e } \\
\text { navios a } \\
\text { vapor, } \\
\text { máquinas } \\
\text { ferramentas, } \\
\text { equipamentos } \\
\text { ferroviários }\end{array}$ & $\begin{array}{c}\text { Engenharia e } \\
\text { equipamentos } \\
\text { elétricos, } \\
\text { engenharia e } \\
\text { equipamentos } \\
\text { pesados }\end{array}$ & $\begin{array}{l}\text { Automóveis e } \\
\text { caminhões, } \\
\text { tratores e } \\
\text { tanques, indústria } \\
\text { aeroespacial, } \\
\text { bens duráveis, } \\
\text { petroquímicos }\end{array}$ & $\begin{array}{l}\text { Equipamentos } \\
\text { de informática e } \\
\text { telecomuni- } \\
\text { cações, } \\
\text { robótica, } \\
\text { serviços info } \\
\text { intensivos, } \\
\text { softwares }\end{array}$ \\
\hline $\begin{array}{l}\text { Infra- } \\
\text { estrutura }\end{array}$ & $\begin{array}{l}\text { Canais, } \\
\text { estradas }\end{array}$ & $\begin{array}{c}\text { Ferrovias, } \\
\text { navegação } \\
\text { mundial }\end{array}$ & Energia elétrica & $\begin{array}{c}\text { Auto-estradas, } \\
\text { aeroportos, } \\
\text { caminhos aéreos }\end{array}$ & $\begin{array}{c}\text { Redes e } \\
\text { sistemas } \\
\text { information } \\
\text { highways" }\end{array}$ \\
\hline $\begin{array}{l}\text { Outros } \\
\text { serviços } \\
\text { crescendo } \\
\text { rapidamente }\end{array}$ & $\begin{array}{l}\text { Máquinas a } \\
\text { vapor, } \\
\text { maquinaria }\end{array}$ & $\begin{array}{c}\text { Aço, } \\
\text { eletricidade, } \\
\text { gás, corantes } \\
\text { sintéticos, } \\
\text { engenharia } \\
\text { pesada }\end{array}$ & $\begin{array}{c}\text { Indústria } \\
\text { automobilística e } \\
\text { aeroespacial, } \\
\text { rádio e } \\
\text { telecomunicações, } \\
\text { metais leves, bens } \\
\text { duráveis, petróleo } \\
\text { e plásticos }\end{array}$ & $\begin{array}{l}\text { Fármacos, } \\
\text { energia nuclear, } \\
\text { microeletrônica, } \\
\text { telecomunicações }\end{array}$ & $\begin{array}{c}\text { Biotecnologia, } \\
\text { nanotecnologia, } \\
\text { atividades } \\
\text { espaciais }\end{array}$ \\
\hline $\begin{array}{l}\text { Países } \\
\text { líderes }\end{array}$ & $\begin{array}{c}\text { Grã-Bretanha, } \\
\text { França e } \\
\text { Bélgica }\end{array}$ & $\begin{array}{c}\text { Grã- } \\
\text { Bretanha, } \\
\text { França; } \\
\text { Bélgica, } \\
\text { Alemanha e } \\
\text { EUA }\end{array}$ & $\begin{array}{l}\text { Alemanha, EUA, } \\
\text { Grã-Bretanha, } \\
\text { França, Bélgica, } \\
\text { Suíça e Holanda }\end{array}$ & $\begin{array}{c}\text { EUA, Alemanha, } \\
\text { outros países da } \\
\text { CEE, Japão, } \\
\text { Rússia, Suécia, } \\
\text { Suíça }\end{array}$ & $\begin{array}{c}\text { Japão, EUA, } \\
\text { Alemanha, } \\
\text { Suécia, outros } \\
\text { países da CEE, } \\
\text { Taiwan e Coréia }\end{array}$ \\
\hline
\end{tabular}

Fonte: Extraído de Dicken (1998). 
Michael Porter (1993), no final dos anos 1980, passou a pesquisar o que havia de especial no ambiente de negócios de algumas nações que as tornava mais desenvolvidas e avançadas que outras; assim como, por que em outros casos, nações não conseguiam avançar ou melhorar as condições de vida de suas populações. Dessa forma, no início dos anos 1990, divulgou o resultado de uma pesquisa que abrangeu dez países - infelizmente nenhum deles na América Latina - e a partir da mesma criou um modelo para análise de situações que ele mesmo denominou de "modelo do diamante". Uma das constatações iniciais de sua pesquisa é a de que não são as nações que são desenvolvidas ou poderosas economicamente, mas sim as empresas que têm sede nesses países. Ou seja, os Estados Unidos, por exemplo, têm uma importância enorme na economia mundial, mas esse mérito se deve ao grande número de empresas com sede nesse país que ocupam posições de destaque no cenário global.

Porter (1993) enfatiza que a prosperidade das nações depende da melhoria dos fundamentos microeconômicos da competição. Isso está intimamente relacionado com fatores estritamente locais, como a existência de clusters, o tipo de demanda existente por parte dos consumidores, o grau da rivalidade entre as empresas, as estratégias adotadas pelas mesmas, além de aspectos bem regionais como recursos naturais e competências específicas e qualificações em recursos humanos.

Michael Porter possui um artigo clássico sobre esse assunto, escrito por ele juntamente com Scott Stern em 2002, na Sloan Management Review, denominado "Innovation: location matters". Nesse artigo, Porter e Stern criticam a ênfase que normalmente tem sido dada à discussão a respeito do ambiente interno das empresas como um fator preponderante para o surgimento de inovações tecnológicas. Segundo eles, “... o ambiente externo é, no mínimo, tão importante quanto o interno para a inovação...”. Prosseguem dizendo que a localização geográfica é crucial para a inovação e que a gestão das inovações pelas empresas tem que ser feita de acordo com a região onde a empresa está instalada. Segundo Stern e Porter, a fertilidade da localização geográfica no tocante à inovação também varia significativamente conforme o setor de atividade; e exemplificam: os Estados Unidos ofereceram um ambiente particularmente atraente para inovação em produtos farmacêuticos nos anos 1990, ao mesmo tempo em que a Suécia e a Finlândia atingiram extraordinários índices de inovação na área de comunicação sem fio.

Peter Dicken (1998), ao chamar a atenção para a importância da geografia e do espaço no surgimento de inovações tecnológicas, destaca quais são esses aspectos locais que devem ser levados em consideração:

... a geografia desempenha um papel fundamental no processo de inovação e aprendizagem, na medida em que as inovações na maioria das vezes são menos o 
resultado de empresas individuais e sim as de um conjunto de recursos, conhecimentos e outros inputs e capacidades que estão localizados em lugares específicos. A reunião destes inputs como pesquisa \& desenvolvimento das universidades e das empresas, aglomeração de empresas manufatureiras em setores afins, e network de provedores de serviços acaba por criar economias de escala, facilidades no compartilhamento de conhecimento, e fertilização cruzada de idéias promovendo interações cara a cara que acabam por permitir a verdadeira transferência de tecnologia... .

Mas, e a América Latina? Um dos objetivos do presente artigo é justamente tentar estabelecer as relações entre as condições geográficas da América Latina e o surgimento de inovações tecnológicas no interior das grandes empresas locais. Além de procurar mostrar em quais setores da economia local estariam as melhores condições para tal desenvolvimento.

\section{O panorama tecnológico da América Latina}

Até o início do século XVI, alguns dos povos que habitavam a América Latina, principalmente os astecas, maias e incas, detinham conhecimentos científicos e tecnológicos muitas vezes superiores aos que, à mesma época, existiam na Europa ou na China. Em algumas áreas como astronomia, botânica, farmacologia e metalurgia, os espanhóis assimilaram os conhecimentos adquiridos na região e os disseminaram pela Europa.

Hoje, no entanto, a América Latina deixou de ser um importante provedor de conhecimentos científicos e tecnológicos, pois apesar de representar cerca de $9 \%$ da população mundial, a região toda corresponde a apenas $1,6 \%$ do total investido globalmente em Ciência \& Tecnologia. Segundo a OCDE - Organização para a Cooperação Econômica e o Desenvolvimento -, em 2001, o mundo investiu cerca de US\$ 587 bilhões nessa área. Do total desse investimento, apenas US\$ 9,4 bilhões foram gastos pelos países latino-americanos. Isso representou cerca de 0,7\% do PIB somado dos países da região, o que não deixa de representar um avanço em relação aos anos 1980. Nessa época, a média de gastos com Pesquisa \& Desenvolvimento dos países da região em relação ao PIB era de apenas 0,45\% (Malecki, 1997), contra 2,0\% na média européia e 2,9\% nos Estados Unidos.

O Quadro 2 mostra quanto alguns países investiram em P\&D em 2003 segundo a OCDE. Por ele se percebe que mesmo o país latino-americano que mais gasta com P\&D, que é o Brasil, está muito abaixo do que gastam os países desenvolvidos. Esse é um problema crônico da região que só tem se acentuado com o tempo. O papel da América Latina na área de Ciência \& Tecnologia mundial é cada vez menor. 
Quadro 2

Gastos de alguns países com Ciência \& Tecnologia em relação aos PIBs em 2003

\begin{tabular}{|l|}
\hline 3,9 Suécia \\
\hline 2,9 Japão \\
\hline 2,9 Coréia do Sul \\
\hline 2,7 Estados Unidos \\
\hline 2,3 Alemanha \\
\hline 2,2 França \\
\hline 2,2 Média para os países da OCDE \\
\hline 1,9 Reino Unido \\
\hline 1,0 BRASIL \\
\hline 0,4 \\
\hline 0,3 Argentina \\
\hline
\end{tabular}

Fonte: $<$ www.oecd.org $>$.

Erber (2000) aponta três razões estruturais para comprovar a dificuldade e a pouca atenção com a questão tecnológica no continente latino-americano:

1. A desproporção entre o peso econômico da região e os esforços feitos em C\&T, sejam eles expressos pelos gastos com pesquisa e desenvolvimento ou pelo número de publicações científicas e patentes depositadas nos EUA;

2. O claramente melhor desempenho em atividades científicas do que em atividades tecnológicas; e

3. O predomínio de tecnologias importadas, provocando uma limitada articulação entre atividades científicas e tecnológicas na região.

Freeman e Soete (1997) fazem uma retrospectiva histórica do que aconteceu na região comentando que, até o início dos anos 1950, o desenvolvimento industrial em toda a América Latina caracterizou-se pelo reduzido grau de sofisticação tecnológica e pela simples importação de tecnologia, principalmente dos Estados Unidos e Alemanha, que vinha incorporada aos bens de capital. A partir da segunda metade dos anos 1950, vários países introduziram medidas de proteção aos seus respectivos mercados nacionais, tentando eliminar ou substituir as importações. 
Foi nessa época que países da região começaram a produzir bens de consumo durável e bens intermediários com maior complexidade tecnológica. A estratégia seguida basicamente por Brasil, Argentina e México foi a de buscar investimento por parte de empresas estrangeiras, principalmente no segmento das montadoras de automóveis. Os respectivos governos também investiram, mas nos segmentos de maior prazo de maturação, como os de matérias-primas e de infraestrutura, mas não em setores de média ou alta densidade tecnológica. O que ocorreu é que se avolumou muito a importação explícita de tecnologia e de serviços tecnológicos sem que houvessem esforços internos aos países para absorver essas tecnologias.

Desde meados dos anos 1960, em todos esses países assiste-se à criação de vários institutos e centros de Pesquisa \& Desenvolvimento de caráter público. No entanto, poucos foram aqueles que mereceram verbas e atenções especiais dos respectivos governos. Apesar disso, alguns deles foram decisivos para a criação de pesquisa de qualidade nos setores econômicos em que atuam ou atuaram. E hoje desempenham um papel fundamental. Apenas para ficar em dois exemplos brasileiros, destaca-se o CTA - Centro Tecnológico da Aeronáutica -, que é considerado o principal responsável pelo sucesso da Embraer, e a Embrapa Empresa Brasileira de Agropecuária -, considerada responsável pela maior parte das pesquisas que resultaram no enorme aumento da produtividade da agricultura brasileira nos últimos anos. Malecki (1997) considera que o que aconteceu no Brasil nessas duas áreas deveria ser um modelo do que deveria ter sido seguido por outros países latino-americanos.

Ainda segundo Malecki, o panorama geral da tecnologia na América Latina mostra que as instituições são fracas e as considerações políticas predominam, o que acaba acarretando a falta de estratégias de longo prazo para Ciência \& Tecnologia e o pouco envolvimento do setor privado, como iremos discutir posteriormente na Seção 4 do presente artigo.

\section{Enquadramento das grandes empresas latino-americanas de acordo com a densidade tecnológica dos setores em que atuam}

O objetivo desta seção é demonstrar que nem mesmo as maiores empresas latino-americanas podem ser consideradas como expressivas e atuantes nas áreas em que ocorrem os mais importantes desenvolvimentos tecnológicos. Malecki (1997) menciona que os dois indicadores mais utilizados para definir o que são setores de alta tecnologia são: 1. Intensidade dos esforços em Pesquisa \& Desenvolvimento em cada setor, medida pela percentagem das vendas que é gasta com P\&D; e 2. Percentagem de trabalhadores bastante técnicos, como engenheiros, cientistas e tecnólogos em relação ao total de trabalhadores do setor. Com base nesses critérios, Malecki apresenta uma tabela elaborada pela OECD em 
1995 classificando 23 setores econômicos industriais em três categorias - Alta, Média e Baixa Densidade Tecnológica, sendo que as proporções dos gastos em P\&D sobre o total das vendas eram, em média, em cada categoria, de 8,1, 2,5 e 0,5, respectivamente. O Quadro 3 lista esses setores conforme classificados pela OECD em cada uma das três categorias acima citadas. Conhecendo quais são os setores industriais de alta, média e baixa intensidade tecnológica, vamos agora pesquisar em quais deles podemos aglutinar as grandes empresas da América Latina. Para isso precisamos, antes de mais nada, obter a relação das mesmas, o que pode ser feito de diversas formas, no entanto optamos por recorrer às revistas especializadas internacionais na elaboração de rankings de maiores empresas globais. Julgamos válido consultar três publicações: Business Week, Forbes e Fortune. A revista Business Week publica anualmente a relação das 1.200 maiores empresas por valor de mercado. Em sua última edição, existiam 31 empresas latino-americanas das quais 19 fazem parte de setores ligados a serviços como bancos, varejo, serviços de Telecom restando, portanto, apenas 12 empresas ligadas às atividades industriais. Essas 12 empresas estão listadas no Quadro 4. Já a revista Forbes apresenta anualmente a relação das 2.000 maiores empresas do mundo, por meio de um critério misto que considera para cada empresa, o seu valor de mercado, ativos, faturamento e lucros. Dessas organizações listadas, apenas 46 são latino-americanas, das quais apenas 16 atuam em setores industriais: todas também se encontram na lista mostrada no Quadro 4. Finalmente, na revista Fortune aparecem apenas dez empresas da América Latina entre as 500 maiores ali apontadas, mas dessas dez apenas duas estão ligadas a atividades industriais. Interessante realçar aqui o baixíssimo número de empresas latino-americanas relacionadas nos rankings dessas três revistas. Apenas recapitulando:

$\begin{array}{lcrc} & \text { Conglomerados da } & \text { Total de empresas } & \% \\ \text { América Latina } & \text { listadas } & \\ \text { Forbes } & 31 & 1.200 & 2,5 \\ \text { Fortune } & 43 & 2.000 & 2,1 \\ & 10 & 500 & 2,0\end{array}$

Ou seja, na melhor situação, apenas 2,5\% das empresas globais listadas são provenientes da América Latina. Apenas para se ter uma referência de como o número é baixo, basta comparar com a Coréia do Sul que, em média, apresenta 2,5\% do total de empresas; ou a Austrália, que apresenta $2 \%$ do total de empresas nas relações acima. Lembrando que a Coréia do Sul possui 48 milhões de habitantes e a Austrália apenas 21 milhões, contra a América Latina toda, que possui 540 milhões de habitantes.

No Quadro 4 estão listadas somente as principais empresas industriais da América Latina por país de origem e por setor industrial, e o mesmo foi elaborado com base nas listas das três revistas acima mencionadas. $O$ que se vê, pelo 
Quadro 4, é que, das 24 maiores empresas latino-americanas, 18 empresas têm sua sede ou no México ou no Brasil. Interessante, agora, verificarmos o que acontece quando enquadramos essas organizações nos setores mencionados nas três categorias de Malecki: Alta, Média e Baixa Densidade Tecnológica. Assim, percebemos que aparece apenas um setor de alta tecnologia, que é o setor aeroespacial. Há três setores considerados de média densidade tecnológica, que são o químico, o de manufaturas e o de não-ferrosos. E, finalmente, há cinco setores de baixa densidade tecnológica, que são os restantes: Alimentos e Bebidas, Extração, Aço, Papel e Celulose e Petróleo. Dessa forma, verificamos que, das 24 maiores empresas industriais latino-americanas, apenas uma, a Embraer, pode ser considerada como de alta tecnologia. Há apenas quatro empresas que se enquadram entre os setores de média intensidade tecnológica e a grande maioria das 24 empresas, ou seja, 19 organizações (80\%) referem-se a setores de baixa intensidade tecnológica.

Quadro 3

Classificação dos setores econômicos conforme a densidade tecnológica

1. Alta Densidade Tecnológica - P\&D sobre total vendas $=8,1 \%$

Aeroespacial

Farmacêutica

Computadores (hardware e software)

Equipamentos de telecomunicações

Semicondutores

Instrumentos Científicos

Máquinas elétricas

2. Média Densidade Tecnológica $-\mathrm{P} \& \mathrm{D}$ sobre total vendas $=2,5 \%$

Motores para veículos

Química

Outras Indústrias Manufatureiras

Máquinas não elétricas

Borracha e Plásticos

Metais não-ferrosos

Outros equipamentos de transporte

3. Baixa Densidade Tecnológica $-\mathrm{P} \& \mathrm{D}$ sobre total vendas $=0,5 \%$

Minerais

Alimentos, Bebidas e Tabaco

Construção de Navios

Petróleo

Aço e ferro

Produtos metálicos

Papel

Móveis e produtos de madeira

Têxtil, Calçados e produtos de couro

Fonte: OCDE citado por Malecki (1997). 
Quadro 4

As maiores empresas industriais da América Latina por país e por setor da economia

\begin{tabular}{|c|c|c|c|c|c|c|}
\hline $\begin{array}{l}\text { Conteúdo } \\
\text { Tecnológico }\end{array}$ & Setor & Brasil & México & Chile & Outros & Total \\
\hline Alto & Aeroespacial & Embraer & & & & \\
\hline Médio & Químico & Braskem & Alfa & & & 2 \\
\hline Médio & Manufaturas & & Carso & & & 1 \\
\hline Médio & Não-Ferrosos & & Cemex & & & 1 \\
\hline Baixo & Minerais & Vale & México & $\begin{array}{l}\text { Antofagasta, } \\
\text { SQM }\end{array}$ & & 4 \\
\hline Baixo & $\begin{array}{l}\text { Bebidas/ } \\
\text { Alimentos }\end{array}$ & Ambev & $\begin{array}{l}\text { Femsa, } \\
\text { Modelo, } \\
\text { Bimbo }\end{array}$ & & & 4 \\
\hline Baixo & Aço & $\begin{array}{l}\text { Usiminas, } \\
\text { CSN, } \\
\text { Gerdau }\end{array}$ & & & $\begin{array}{l}\text { Tenaris } \\
\text { (Arg.) }\end{array}$ & 4 \\
\hline Baixo & Petróleo & $\begin{array}{l}\text { Petrobrás, } \\
\text { Ipiranga }\end{array}$ & Pemex & Copec & $\begin{array}{l}\text { PDVSA } \\
\text { (Ven.) }\end{array}$ & 5 \\
\hline Baixo & Papel & Aracruz & & CMPC & & 2 \\
\hline Total & & 10 & 8 & 4 & 2 & 24 \\
\hline
\end{tabular}

Fonte: Elaborado pelo autor, pesquisando as revistas Forbes, Fortune e Business Week.

Esses dados, por si sós, são muito preocupantes, e se formos verificar um outro estudo recente, e muito importante, feito pela Booz Allen acerca das 1.000 maiores empresas do mundo por gastos na busca de inovações tecnológicas, vamos comprovar que a situação das empresas latino-americanas é realmente das piores. Nessa pesquisa, denominada “Money isn't everything - Booz Allen Hamilton Global Innovation 1000”, realizada e divulgada em 2005, a Booz Allen fez um extensivo levantamento junto às maiores empresas do mundo para verificar quanto cada uma gastava com Pesquisa \& Desenvolvimento e, dessa forma, estabeleceu um ranking dos gastos por empresas. As 20 primeiras com os respectivos gastos em P\&D em bilhões de dólares no ano 2004 estão mostradas no Quadro 5.

Nessa relação das 1.000 empresas, aparece uma única da América Latina, que é a brasileira Petrobras e está na posição 277, com um gasto em P\&D de US\$ 238 milhões em 2004, o qual representou apenas 0,6\% do seu faturamento de US\$ 37 bilhões. Sem dúvida, esse é um dos dados mais preocupantes do estudo da Booz Allen, ou seja, a quase total ausência de empresas latino-americanas nessa relação. Outro dado interessante é a origem por setores da economia das 1.000 empresas e, consequientemente, em quais setores o gasto com P\&D é maior. Para essa análise, o estudo classificou as 1.000 empresas em 11 categorias de setores, mostrados no Quadro 6, acompanhados da informação de quanto do total de US\$ 384 bilhões foi gasto em cada setor em P\&D em 2004. 
Quadro 5

As maiores empresas do mundo em gastos de P\&D em bilhões de dólares em 2004

\begin{tabular}{|ll|}
\hline 1. Microsoft & 7,78 \\
2. Pfizer & 7,68 \\
3. Ford & 7,40 \\
4. Daimler-Chrysler & 7,03 \\
5. Toyota & 7,02 \\
6. General Motors & 6,50 \\
7. Siemens & 6,16 \\
8. Matsushita Electric & 5,73 \\
9. IBM & 5,67 \\
10. Johnson \& Johnson & 5,20 \\
11. GlaxoSmithKline & 5,20 \\
12. Intel & 4,78 \\
13. Volkswagen & 4,72 \\
14. Sony & 4,67 \\
15. Nokia & 4,64 \\
16. Honda & 4,35 \\
17. Samsung Electronics & 4,32 \\
18. Novartis & 4,20 \\
19. Roche & 4,07 \\
20. Merck & 4,01 \\
\hline
\end{tabular}

Fonte: Booz Allen <www.bah.com>.

Se voltarmos para o Quadro 4, onde estão relacionadas as 24 maiores empresas latino-americanas, veremos que nenhuma delas faz parte dos dois setores mais importantes do ponto de vista de gastos em tecnologia, segundo esse estudo da Bozz Allen e que são os setores de Saúde (aí incluída a indústria farmacêutica) e o de Software. Na próxima seção nos deteremos nesse aspecto.

\section{Quadro 6}

Gastos em P\&D em cada setor da economia em bilhões de dólares em 2004

\begin{tabular}{|lcr|}
\hline 1. Tecnologia da Informação e Eletrônica & $\$ 96,2$ & $25 \%$ \\
2. Saúde (Farmacêutica) & $\$ 79,2$ & $21 \%$ \\
3. Automobilística & $\$ 69,4$ & $18 \%$ \\
4. Tecnologia (inclui maquinário pesado) & $\$ 29,8$ & $8 \%$ \\
5. Energia e Química (inclui petróleo) & $\$ 25,5$ & $7 \%$ \\
6. Software e Internet & $\$ 20,5$ & $5 \%$ \\
7. Indústrias manufatureiras em geral & $\$ 18,2$ & $5 \%$ \\
8. Consumo & $\$ 14,3$ & $4 \%$ \\
9. Aeroespacial e Defesa & $\$ 12,2$ & $3 \%$ \\
10. Telecom & $\$ 8,8$ & $2 \%$ \\
11. Outros & $\$ 9,8$ & $2 \%$ \\
Total & $\$ 384$ & $100 \%$ \\
\hline
\end{tabular}

Fonte: Booz Allen <www.bah.com $>$. 


\section{O porquê do pequeno envolvimento das empresas e das nações latino- americanas com as questões tecnológica}

A abundância de recursos naturais na América Latina tem sido apontada como uma explicação importante para a baixa preocupação com a inovação que predomina na região. Fairbanks e Lindsay (2000) afirmam que os empresários locais tendem a pressupor que as vantagens em recursos naturais, matérias-primas abundantes e mão-de-obra barata proporcionam a eles posições de liderança nos mercados exportadores e, assim, deixam de criar condições para a inovação. Adotando essa filosofia, são constantemente ultrapassados por países da Ásia ou da África, que conseguem ou baratear ainda mais o custo de sua mão-de-obra, ou entram no mercado internacional vendendo um recurso natural a um preço ainda mais baixo do que vinha sendo praticado por eles. Além disso, Fairbanks e Lindsay (2000) apontam outra razão importante para a inexistência de inovações: trata-se da cooperação deficiente entre as empresas. Segundo eles, não existe a cultura da cooperação entre as empresas da região. Ao contrário de países como a Itália, onde a existência dos clusters, também chamados de agrupamentos industriais, promove a cooperação e incentiva as empresas a se unirem para, por exemplo, buscar conjuntamente mercados externos, lançar uma nova marca, ou então investir conjuntamente em P\&D (Pesquisa \& Desenvolvimento), na América Latina, quase que invariavelmente, os empresários só enxergam nos concorrentes inimigos a serem abatidos.

Isso contribui para criar, dentro de cada setor, um clima de desconfiança que sempre aniquilou qualquer possibilidade de cooperação. Honrosas exceções constituem as montadoras automobilísticas e suas relações com as fornecedoras de autopeças tanto na Argentina, como no Brasil ou no México. Mas esse desvio da regra, provavelmente, se deva ao fato de esses serem setores nos quais ocorre a predominância do capital estrangeiro.

Essa ausência de cooperação empresarial também explica o pequeno número de clusters na região e, como reafirmam Fairbanks e Lindsay (2000): “... notamos uma profunda ausência de clusters de setores correlatos ou de apoio, e uma correspondente falta de inovação: empresas que não cooperam entre si não são capazes de aprender umas com as outras".

Peter Dicken (1998) enfatiza que uma característica importante no desenvolvimento de países do Terceiro Mundo, sejam eles asiáticos ou latinoamericanos, é a forte presença do Estado. No entanto, o autor assinala o fato de que na América Latina os governos não foram tão bem-sucedidos como na Ásia. Segundo ele, a razão principal para o insucesso dos vários governos desses países foi a falta de preocupação com o aumento da capacitação interna com vistas a aumentos de exportações. Enquanto, na Ásia, a preocupação maior era o 
crescimento das exportações de produtos industrializados, na América Latina a ênfase era na substituição de importações.

Dicken chama a atenção para o fato de que a antiga divisão de trabalho, quando as nações desenvolvidas produziam bens manufaturados e as nações em desenvolvimento vendiam suas commodities, sejam estas minerais ou produtos agrícolas, não é mais válida. Hoje o fluxo de mercadorias pelo mundo é extremamente complexo e se tornou possível graças à fragmentação das cadeias produtivas. No entanto, o que vemos na prática é a existência de algumas cadeias produtivas que se estendem por vários países da América Latina, mas que são quase que totalmente comandadas por empresas com sede em países do Primeiro Mundo. Como exemplos dessas cadeias podemos citar os setores automobilístico, farmacêutico, equipamentos de informática e de telecomunicações, o setor de bens eletrônicos de consumo, e o setor químico.

De uma forma geral, as empresas desses setores estão na América Latina em busca do rentável mercado, cujo tamanho não é pequeno, e também na intenção de obter mão-de-obra barata para empregar em suas linhas de produção, o que na grande maioria dos casos se limita à montagem final de bens. Qualquer etapa do vasto processo das cadeias de valor das empresas globais deixará de ser realizado nas respectivas subsidiárias da América Latina, se nessa etapa houver necessidade de algum desenvolvimento tecnológico. Nessa hipótese, será realizada certamente na sede principal de tais empresas que, em geral, está na América do Norte ou na Europa ou no Japão.

Jorge Larraín (apud Gwynne, 1999), ao explicar por que a América Latina não avançou tanto como a Ásia nos últimos 20 anos, atribui boa parte desse atraso ao fechamento de mercado e ao protecionismo que predominou em nossa região nos anos 1970 e 1980; isso porque essa suspensão não expôs as empresas da região à competição internacional, e também acabou adiando a construção da infra-estrutura para que os pesquisadores locais possuíssem os meios necessários para desenvolver seus trabalhos.

Nessa mesma linha de pensamento, Chris Freeman e Luc Soete (1997), ao compararem o desenvolvimento econômico de algumas nações da Ásia, especialmente Coréia do Sul e Taiwan, com o progresso da América Latina na década de 1980 chamam a atenção para a importância das diferenças que existem em alguns poucos aspectos. Fatos, segundo os autores, que foram decisivos para explicar o enorme crescimento dos tigres asiáticos e a estagnação das nações latino-americanas naquele período. Para eles, as cinco deficiências abaixo citadas estão entre os principais problemas do continente quando comparado com os tigres asiáticos: 
1. Sistema educacional deteriorado com baixa formação de engenheiros;

2. Muita transferência de tecnologia, especialmente dos Estados Unidos, mas baixa capacidade de absorção devido ao pequeno investimento das empresas locais em Pesquisa \& Desenvolvimento;

3. Fraca infra-estrutura de Ciência \& Tecnologia;

4. Atraso no desenvolvimento das telecomunicações; e

5. Nenhuma ênfase ao setor de produtos eletrônicos.

Porém, existe algo que os governos podem fazer para tornar seus países mais férteis em inovações? Segundo Porter e Stern (2002), conforme mencionado no relatório já referido anteriormente, a resposta é sim. Mas com ressalvas, pois os governos são apenas um dos componentes de um grande conjunto de fatores presentes no ambiente empresarial dos países que afeta a capacidade de inovação. E, seguramente, segundo eles não é o mais importante.

Para que um dado setor econômico de um determinado país tenha propensão a inovar, existem dez fatores cruciais. Esses pontos já haviam sido identificados por Porter em seu livro "A Vantagem Competitiva das Nações”. No entanto, naquela ocasião sua preocupação era mostrar o que faz com que um setor econômico em um determinado país consiga ter projeção e sucesso mundiais. Agora, com Stern, Porter arrola praticamente o mesmo conjunto de fatores, mas enfatizando que são eles que garantem o surgimento de inovações. Não se pode discordar de Porter de que se um dado setor econômico em um país é palco de inovações tecnológicas bem-sucedidas, então há grandes chances de que esse mesmo setor venha a ser considerado de excelência mundial. Os fatores considerados importantes por Porter e Stern são os seguintes:

1. Recursos Humanos de alta qualidade;

2. Sólida Infraestrutura de pesquisa em Universidades;

3. Infraestrutura de informação de alta qualidade;

4. Ampla oferta de capital de risco;

5. Presença de clusters em vez de empresas isoladas;

6. Rede de fornecedores de alta competência/excelência;

7. Consumidores exigentes e demandantes de qualidade e sofisticação

8. Consumidores que criam a demanda de forma pioneira e inédita antes que outros consumidores em outros países o façam;

9. Intensa rivalidade entre as empresas locais do setor em questão;

10. Contexto local que encoraje o investimento em pesquisa. 
Ao percorrer esse conjunto de dez fatores, é fácil perceber que, em sua grande maioria, eles realmente inexistem ou são muito fracos em toda a América Latina. Talvez a única exceção seja o item 6 - rede de fornecedores de alta competência/excelência. Isso pelo desenvolvido parque industrial do Brasil secundado pelo México.

Um dos economistas contemporâneos mais respeitados e que mais tem estudado a relação entre desenvolvimento econômico e tecnologia é o Prêmio Nobel de 2000, Joseph Stiglitz, que escreveu juntamente com Carl Walsh um livro sobre microeconomia em que destaca o papel da tecnologia. Stiglitz e Walsh (2003) comentam que as duas formas mais importantes e consensuais de que governos se devem utilizar para encorajar as atividades inovadoras são a proteção ao sistema de patentes e o apoio à pesquisa básica. Além disso, Stiglitz e Walsh defendem que governos concedam subsídios para empresas desenvolverem novas tecnologias. Ao contrário de Porter e Stern (2002), eles são a favor de uma forte atuação governamental para favorecer o surgimento de inovações por parte das empresas. Mesmo assim, reconhecem que a atividade de pesquisa está cada vez menos ao alcance da pequena empresa por várias razões, mas principalmente pelo fato de bancos não concederem empréstimos para esse tipo de atividade. Com isso, aumenta a importância dos subsídios, segundo Stiglitz e Walsh.

No entanto, concessão de incentivos fiscais para projetos de Pesquisa \& Desenvolvimento é assunto pouco prioritário na agenda da grande maioria dos governos dos países latino-americanos. O país mais adiantado nesse tema é o Brasil, que apenas recentemente aprovou uma legislação de apoio à inovação, mas que apenas timidamente tateia a questão dos incentivos.

Cumpre destacar que Porter e Stern mencionam a América Latina e destacam como grandes vulnerabilidades da região, no que diz respeito ao surgimento de inovações, a pouca ligação entre as empresas e as universidades. De acordo com os autores, "o sistema de ensino superior na América Latina tem pouca ligação com as empresas e muito pouco envolvimento com as políticas nacionais voltadas para ciência e tecnologia". Isso é confirmado por outros autores que se dedicaram a analisar a questão científica e tecnológica do continente. Sagasti (1981) aponta como um dos problemas crônicos da América Latina o enorme distanciamento entre a produção de ciência e a geração de tecnologia, o que, segundo ele, é uma conseqüência da inexistência de relação entre a universidade e a empresa.

Esse mesmo aspecto é colocado por Millan e Concheiro (2000), quando analisam as razões do atraso do México nas questões de Ciência \& Tecnologia. Eles vão além, mencionando que uma razão adicional para o atraso do país nessa questão é a falta de uma política industrial que defina as áreas prioritárias para 
investimentos, e deixam bem caracterizado que, ao contrário dos países mais desenvolvidos nos quais quem mais investe em Pesquisa \& Desenvolvimento são as empresas, no caso do México esse gasto é em sua maior parte feito pelo governo. Assim, enquanto no Japão, na Alemanha e Estados Unidos as empresas privadas são responsáveis respectivamente por $67,1 \%, 61,1 \%$ e $58,4 \%$ do total dos gastos com P\&D, no México esse valor é de apenas $17,6 \%$.

Essa, aliás, é também uma característica do Brasil conforme mostrado no texto produzido pelo professor Carlos Henrique Brito Cruz, em 2002, "A Universidade, a Empresa e a Pesquisa". Nesse trabalho, Cruz compara Brasil e Coréia em função do número de engenheiros, cientistas e pesquisadores que trabalham ligados a Pesquisa \& Desenvolvimento. Apesar de o nosso país ter uma população quatro vezes superior à da Coréia, a quantidade de trabalhadores nessas funções é maior na Coréia chegando a 159.773 pessoas, enquanto no Brasil totaliza 125.645 pessoas - ambos os dados referidos a 2001. Mas, no Brasil, somente $23 \%$ dessas pessoas estão em empresas privadas, enquanto na Coréia essa percentagem é de 59\%. Assim, a grande maioria dos brasileiros que trabalham em pesquisa, cerca de $77 \%$ do total dos pesquisadores, está ou na universidade ou nos institutos mantidos pelo governo, enquanto na Coréia trabalham nessas instituições apenas $41 \%$ dos pesquisadores.

Em 1999, a revista britânica Nature produziu uma edição especial chamada "Ciência na América Latina". No artigo dedicado ao México, consta uma análise importante sobre um fato que ajuda a explicar os números acima e que se repete por todo o continente:

Parte do problema é cultural. O México herdou a tradição européia do cientista como acadêmico e não o modelo norte-americano do cientista inventor e empresário. Para um pesquisador universitário ter ligação com a indústria é considerado prostituição pelos colegas. Do lado da indústria, não há forte tradição de investimento em P\&D. Até o início dos anos 80, o México tinha uma política industrial de propriedade estatal e protecionismo que resultava em pouco incentivo ao investimento em inovação. Agora as empresas querem modernizar sua tecnologia, mas voltam-se mais para as empresas estrangeiras atrás de ajuda, e não se mostram dispostas a esperar o tempo necessário para que a ciência e a tecnologia nacionais encontrem respostas para suas necessidades.

Em suma, há várias razões para que o envolvimento das empresas e dos países da América Latina com desenvolvimento tecnológico seja pequeno. Mas, para finalizar essa relação, não se pode deixar de mencionar os aspectos culturais e a análise amarga de Montaner:

A real tragédia da América Latina é que o capital é limitado e boa parte dele está em mãos de empresários não comprometidos com o risco ou com a inovação mas sim com a especulação... Não são capitalistas modernos mas atuam como senhores da terra de tradição feudal. 


\section{Considerações finais}

A América Latina é muito rica em recursos naturais e de uma forma geral sua mão-de-obra é barata. Esses foram os principais ingredientes que fomentaram as grandes empresas originárias da região, com raríssimas exceções. Por conta desses fatores, nosso continente ostenta algumas empresas poderosas, mas quase sempre atuantes em setores que foram importantes no século XIX, mas que deixaram de ser relevantes neste século XXI. Ser ator global em setores como bebidas, cimento, mineração, agricultura, pesca ou aço não é de todo mau, mas não é suficiente. Como vimos, os países mais avançados apresentam empresas nos setores que hoje dominam a economia mundial como telefonia, software, hardware, equipamentos médicos ou a indústria farmacêutica. Em outras palavras, podemos dizer que mesmo as grandes empresas latino-americanas de uma forma geral estão fora dos setores de alta tecnologia, com raríssimas exceções como a brasileira Embraer. Empresas do nosso continente quando conseguem porte e projeção para atuar no mercado mundial estão em setores de baixa tecnologia na maioria dos casos produzindo commodities: Petrobras e Cemex são ótimos exemplos.

Esse aspecto é por demais significativo, pois, como vimos anteriormente, nos países mais avançados quem mais gera inovações e tecnologia é a grande empresa, cabendo aos governos o papel de criar as condições para que essas empresas possam florescer. Isso representa um problema para a América Latina, pois o número de grandes empresas é limitado quando comparado com o Primeiro Mundo. Como vimos, menos de $2,5 \%$ das grandes empresas globais são originárias da nossa região.

É nesse aspecto que está a principal dificuldade para a América Latina ser uma importante geradora de tecnologias, ou seja, na inexistência de grandes empresas originárias da região. Como vimos são os grandes conglomerados globais os maiores investidores em Pesquisa \& Desenvolvimento. Ou seja, no fundo, quem cria as novas tecnologias não são mais nem as universidades nem os governos, mas são as empresas, que, como mostrou o estudo da Booz Allen, investem somas enormes em P\&D.

Mesmo os grandes grupos empresariais latino-americanos são pequenos (em termos de faturamento e patrimônio líquido) quando comparados aos grupos empresariais dos países desenvolvidos ou, até mesmo, de países como a Coréia e Taiwan. Como quase todos os setores industriais e de serviços estão se concentrando, tamanho passa a ser fundamental. A empresa que tem uma grande dimensão possui também capacidade administrativa, mercadológica e tecnológica por causa das economias de escala. Tanto a economia japonesa como a coreana 
cresceram baseadas num modelo de conglomerados composto por grandes empresas em torno dos quais giram outras empresas médias e pequenas.

Os governos dos países mais avançados já perceberam, há tempos, que a competitividade das nações é resultado da competitividade de suas empresas e que, portanto, o que lhes compete é criar as condições para que suas empresas locais possam concorrer internacionalmente. Por isso dão toda atenção ao suporte necessário de Ciência \& Tecnologia. Mas também já sabem que nenhuma nação pode ser auto-suficiente em todas as tecnologias. Assim, os Estados Unidos se aperfeiçoaram e criam tecnologia em áreas como farmacêutica, informática e telecomunicações, a Alemanha em mecânica, o Japão em robótica, a Inglaterra em biotecnologia e genética.

Apesar da importância das empresas na geração de tecnologia, como o presente artigo procurou deixar claro, é inegável que a solução dos problemas não cabe somente a elas: algumas medidas de apoio governamental se fazem necessárias. Segundo Stiglitz e Walsh (2003), os governos devem garantir a proteção à propriedade intelectual, além de investir permanentemente em pesquisa básica, mas também devem criar as condições para o surgimento de investimentos de risco dispostos a apoiar e suportar os investimentos em P\&D. Para isso, os governos precisam criar incentivos e subsídios para esse tipo de investimento. Isso tudo sem esquecer aquele que é o principal papel dos governos nessa área: a atenção ao sistema educacional para que o mesmo forneça os recursos humanos qualificados de que as nações necessitam.

No caso da América Latina, os governos também devem dar uma maior atenção para a necessidade de formação de clusters, pois sem eles fica muito mais difícil o atingimento das economias de escala e escopo, bem como a troca e intercambiabilidade de idéias, como ocorre no caso de outros países.

Mas é claro que o tratamento dessa questão é extremamente difícil e não pode ser imputado somente aos governos. Sem grandes grupos, fortes e saudáveis, e com administração profissional não teremos como competir no difícil cenário da globalização. Esse assunto, um dos quais a que se dedicou a maior atenção no presente artigo, é vital. Claramente, existem sérios problemas de má gestão na empresa latino-americana. É necessário que as sociedades e as próprias empresas se conscientizem desse aspecto, pois caso não haja progresso nesse item, daqui a poucos anos o número de empresas da nossa região com projeção mundial será ainda menor que agora. As escolas de Economia e de Administração têm uma enorme responsabilidade nessa questão.

Basear seu desenvolvimento em recursos naturais não é a única característica referente à geografia da região que afeta a existência ou não de inovações tecnológicas. O baixo investimento em educação, a pequena infra- 
estrutura destinada à pesquisa e mesmo a cultura conservadora e pouco arrojada de empresários que viveram muito tempo sem necessitar competir com produtos estrangeiros acabam por explicar a pequena presença da América Latina no que há de relevante em Ciência \& Tecnologia no mundo de hoje.

No entanto, podemos ter esperanças. Como falamos anteriormente, ao citar os ciclos de Kondratiev, nos últimos 250 anos sempre houve um fator tecnológico que, em média a cada 60 anos, definia o que de importante mudava na economia e na sociedade. Já tivemos quatro ciclos completos e estamos neste momento na quinta onda, a onda da Tecnologia da Informação. Acontece que essa onda está atravessando o seu auge, o que significa que nos próximos anos ela começa a perder importância e uma nova onda estará predominando e definindo a nova dinâmica da economia mundial talvez em 20 anos apenas. Essa sexta onda será a da Biotecnologia e das Ciências da Vida. A América Latina tem amplas condições para se dar bem nessa sexta onda, não só por já estar desenvolvendo pesquisas de qualidade na área mas, principalmente, devido à riqueza que apresenta com sua biodiversidade, mormente na região amazônica, que avança nos territórios de pelo menos cinco países da América do Sul, inclusive o Brasil. Em cada uma das ondas anteriores, países e regiões souberam se beneficiar e aproveitaram-se da respectiva onda para conseguir seu desenvolvimento social graças ao crescimento econômico alcançado. A América Latina não pode perder essa janela de oportunidade.

\section{Referências bibliográficas}

BLACK, J. K. Latin America its problems and its promise. USA: Boulder, 1998.

BLAKEMORE, H.; COLLIER, S.; SKIDMORE, T. Latin America and the Caribbean. New York: Cambridge University Press, 1992.

BOOZALLEN. Money isn't everything - The Booz Allen Hamilton Global Innovation 1000. NewYork, 2005. Disponível em: $<$ http://www.boozallen.com/publication/strategy+business/Winter2005>. Acesso em: 31 ago. 2006.

BRAKMAN, S.; GARRETSEN, H.; VAN MARREWIJK, C. An introduction to geographical economics. Cambridge: University Press, 2005.

BRITO CRUZ, C. H. A Universidade, a Empresa e a Pesquisa. Campinas: Universidade Estadual de Campinas. Instituto de Física Gleb Wataghin. Disponível em: $<$ http://www.ifi.unicamp.br/ brito/artigos/univ-empr-pesq-rev102003b.pdf $>$. Acesso em: 31 ago. 2006.

DEL POZO, P. Aspectos tecnológicos de la modernización industrial de México. México: Fondo de Cultura, 1995.

DICKEN, P. Global shift. New York: The Guilford Press, 1998.

ERBER, F. Perspectivas da América Latina em Ciência \& Tecnologia. Rio de Janeiro: UFRJ, 2000. Mimeografado. 
FAIRBANKS, M.; LINDSAY, S. Arando o mar: fortalecendo as fontes ocultas de crescimento em países em desenvolvimento. Rio de Janeiro: Qualitymark, 2000.

FREEMAN, C.; SOETE, L. The economics of industrial innovation. Cambridge: MIT Press, 1997.

FORBES. The biggest companies in the world. Edição de 17 de abril de 2006.

GALEANO, E. Open veins of Latin America: five centuries of the pillage of a continent. New York: Monthly Review Press, 1997.

GWYNNE, R.; KAY, C. Latin America transformed. London: Arnold, 1999.

KONDRATIEFF, N. The long wave in economic life. Review of Economic Statistics, v. 17, p.105-115, 1925.

KRUGMAN, P. Development, geography and economic theory. Cambridge: MIT Press, 1995.

LANDES, D. Riqueza e a pobreza das nações: por que algumas são tão ricas e outras são tão pobres. Rio de Janeiro: Campus, 1998.

MACILWAIN, C. As chances da América Latina. Nature, n 398, Apr. 1999.

MALECKI, E. Technology \& economic development. London: Longman, 1997.

MARSHALL, A. Principles of economics. London: MacMillan and Co, 1920.

MILlAN, B.; CONCHEIRO, A. México 2030: nuevo siglo, nuevo país. México: Fondo de Cultura, 2000.

MONTANER, C. A. Culture and the behavior of elites in Latin America. In: HARRISON, L. E. (Ed.). Culture matters. New York: Basic Books, 2000, p. 56-64.

ORGANIZATION FOR ECONOMIC CO-OPERATION AND DEVELOPMENT (OCDE). OECD statistical database. Disponível em: <http://www.oecd.org>. Acesso em: jul. 2006.

PORTER, M. A vantagem competitiva das nações. Rio de Janeiro: Campus, 1993.

jan./fev. 2002.

; STERN, S. Inovação e localização de mãos dadas. HSM Management,

SAGASTI, F. Ciencia, tecnología y desarrollo latinoamericano. México: Fondo de Cultura, 1981.

SCHUMPETER, J. Capitalism, socialism and democracy. London: Allen \& Unwin, 1943.

STIGLITZ, J.; WALSH, C. Introdução à microeconomia. Rio de Janeiro: Campus, 2003.

WARSH, D. Knowledge and the wealth of nations. New York: WWNorton, 2006.

Revistas e sites consultados para elaboração do ranking das maiores empresas

Business Week. The BusinessWeek Global 1200. Edição de 26 dez. 2005.

Forbes. 2000 Global. Edição de 17 abr. 2006.

Fortune. Fortune Global 500. Edição de 24 jul. 2006. 